\title{
Designing contemporary fashion footwear using traditional Punjabi Jutti motifs and their consumer preferences
}

Received: 21.12.2017; Revised: 29.03.2018; Accepted: 16.04 .2018

See end of the paper for authors' affiliations Amanjot Kaur Department of Fashion Designing, College of Home Science, Punjab Agricultural University, Ludhiana (Punjab) India

Email : amankaur.ct@gmail.com
ABSTRACT : Punjab, the prosperous state of India has rich cultural heritage. It is the land of vivacity and vitality, exuding warmth and energy through its prosperity and multi- coloured folk culture. Art and craft of Punjab is described as a creation or expression of something beautiful especially in visual form. Among these, the Jutti is one of styles of footwear that has continuously evolved due to numerous influences from near and far. Juttis come in many variations according to regional tradition, period and shoemaker and are adapted according to the environment and materials.For this study forty motifs/designs of traditional Punjabi Jutti were documented from leading stores of local markets of Muktsar and Fazilka, internet, books and magazines etc. through photographs out of which ten Jutti motifs/designs were selected for developing ten designs of footwear with seven style variations of each through CAD. Preferences regarding the developed footwear were taken from 90 respondents, which shows that footwear design $A_{1} B_{4}, C_{2}, D_{6}, E_{5}, F_{5}, G_{1}, H_{7}, I_{2}$ and $J_{2}$ with first rank were selected out of seven style variations of each design. Footwear designs $A_{1}, C_{2}, D_{6}, F_{5}, G_{1}$ and $H_{7}$ were top six ranked designs. It was found that footwear design $\mathrm{C}_{2}$ was given first rank with mean score of 6.86 on the basis of all the parameters.

KEY WORDS: Traditional Punjabi Jutti, Footwear, Design, Respondents, Most preferred

- HOW TO CITE THIS PAPER : Kaur, Amanjot and Saini, Harminder Kaur (2018). Designing contemporary fashion footwear using traditional Punjabi Jutti motifs and their consumer preferences. Asian J. Home Sci., 13 (1) : 158-170, DOI: 10.15740/HAS/AJHS/13.1/158-170. Copyright@ 2018: Hind Agri-Horticultural Society. 